\title{
EUROPE 2020 TARGETS: THE PROGRESS OF THE BALTIC COUNTRIES IN TERMS OF RIS3
}

Sergejs GEMMA, Faculty of Economics and Social Development, Latvia University of Agriculture, Svetes iela 18, Jelgava, LV-3001, Latvia; ef16151@1lu.lv (corresponding author)

Zane VĪTOLIN̦A, Institute of Economics and Regional Development, Faculty of Economics and Social Development, Latvia University of Agriculture, Svetes iela 18, Jelgava, LV-3001, Latvia; zane.vitolina@1lu.lv

The Europe 2020 strategy was proposed by the European Commission with an aim to improve European Union (EU) competitiveness and promote economic growth. For the successful achievement of economic growth using the Smart Specialization Strategy (RIS3) in the EU, the European Commission has set out five interrelated headline targets to be achieved by 2020 in the areas of employment, research and development, climate change and energy, education and poverty and social exclusion. The targets are translated into national targets for each EU Member State; at the same time, they are common goals for all the EU Member States to be achieved through a mix of national and EU actions. The authors of the research used statistical data on the Europe 2020 targets to detect progress or regress in achieving these targets, the accuracy of target value detection and the implementation of RIS3 in the EU.

The aim of the research is to evaluate RIS3 progress based on the Europe 2020 targets. The following tasks were set: 1) To calculate progress on each Europe 2020 target for Estonia, Latvia and Lithuania using Eurostat statistical data; 2) To evaluate the calculated data and compare the data with those for the other Baltic States and the EU average; 3) To forecast RIS3 development for the year 2020 in the Baltic States.

The research employed the monographic and descriptive methods as well as analysis, synthesis, the graphic method, the data grouping method and forecasting.

All the three Baltic States have exceeded their target values on employment and education. Low indicators - just half of the target value - the Baltic States have on the share of the EU's GDP invested in Research and Development. Other positions such as green energy, poverty and social exclusion mostly show a need for more active and effective action for achieving the Europe 2020 targets.

Keywords: Europe 2020 targets, smart specialization strategy

\section{INTRODUCTION}

The economic crisis in 2008 made future economic growth much more difficult. Economically, the European Union (EU) needed an effective recovery and fast growth, improving the EU's competitiveness while maintaining its social market economy model and improving significantly its resource efficiency. Therefore, in 2010 the European Commission proposed the Europe 2020 strategy, which was launched as the EU's strategy for smart, sustainable and inclusive growth. The strategy was conceived as a partnership between the EU and its Member States. It set out five interrelated headline targets for the EU to achieve by 2020 in the areas of employment, research and development (R\&D), climate change and energy, education, and the fight against poverty and social exclusion, striving to deliver high levels of employment, productivity and social cohesion, while reducing the impact on the natural environment. The Europe 2020 targets must be measurable, capable of reflecting the diversity of Member States situations and based on sufficiently reliable data for purposes of comparison (Eurostat, 2017).

The targets are interrelated and critical to our overall success. To ensure that each Member State tailors the Europe 2020 strategy to its particular situation, the Commission proposes that EU goals are translated into national targets and trajectories. The targets are representative of the three priorities of smart, sustainable and inclusive growth (Europe 2020, 2010).

The growth strategy for reaching Europe 2020 targets closely relates to a smart specialization strategy, because the Europe 2020 targets are also focused on smart specialization activities. The underlying rationale behind the smart specialization concept is that by concentrating knowledge resources and linking them to a limited number of priority economic activities, countries and regions can become more competitive in the global economy (Jucevicius R., Galbuogiene A., 2014). Realizing the smart specialization strategy, many of the target values are improved - indeed, the successful transformation of regional economies around key strengths would require more than improving Research \& Innovation framework conditions and raising $R \& D$ intensities. The ideas are about new skills and jobs and the enhancement of Europe's education systems - the main vehicle to reinforce competitiveness is the quality of European

Copyright (C) 2017 The Authors. Published by Aleksandras Stulginskis University. This is an open-access article distributed under the terms of the Creative Commons Attribution License (CC-BY 4.0), which permits unrestricted use, distribution, and reproduction in any medium, provided the original author and source are credited. 
human capital -, as well as about sustainable growth. To contribute to this wide goal, European regions and Member States have to develop better conditions for their industrial base and link instruments from Research \& Innovation domains to those of the industrial policy domain (Eurostat, 2017).

The defined target values must be achieved in the year 2020. Now more than half of the period has passed; therefore it is worthwhile to evaluate progress on the headline targets and the Europe 2020 strategy in general for the first half of the period - from 2011 to 2015 - which targets are following target values set and where some problems with the progress in reaching the target values are.

The aim of the research is to evaluate RIS3 progress based on the Europe 2020 targets. The following tasks were set: 1) To calculate progress on each Europe 2020 target for Estonia, Latvia and Lithuania using Eurostat statistical data; 2) To evaluate the calculated data and compare the data with those for the other Baltic States and the EU average; 3 ) To forecast RIS3 development for the year 2020 in the Baltic States.

\section{RESEARCH METHODS}

The research employed the monographic and descriptive methods as well as analysis, synthesis, statistical analysis, the graphic method, the data grouping method and forecasting.

For the first time, the Europe 2020 targets were defined on 3 March 2010 in the European Commission communication "Europe 2020 - a strategy for smart, sustainable and inclusive growth" as five headline target areas. And legally these targets were published in the European Council Conclusions of $17^{\text {th }}$ June 2010. The European Council has defined the targets to be achieved in 2020:

the employment rate should be $75 \%$ of the population in age $20-64$, including the greater involvement of older workers and women, the better integration of migrants in the work force;

investment in R\&D should be $3 \%$ of the EU's gross domestic products (GDP), focusing attention on the need for both the public and private sectors to invest in $\mathrm{R} \& \mathrm{D}$, more attention should be paid to improving the conditions for private $\mathrm{R} \& \mathrm{D}$ in the $\mathrm{EU}$;

reducing greenhouse gas emissions by at least $20 \%$ compared with 1990 levels, increasing the share of renewable energy sources in energy consumption to $20 \%$; and increasing energy efficiency to $20 \%$;

reducing the dropout rate of early school leavers to $10 \%$ and increasing the share of the younger generation aged $30-34$ having a tertiary degree to at least $40 \%$ in 2020 ;

reducing the number of EU citizens living below the national poverty lines by $25 \%$ and lifting over 20 million people out of poverty (European Council, 2010).

To achieve these targets commonly, each EU Member State has defined its own target values for 2020. The target values for each member state were set to reflect the situation and possibilities of each Member State to contribute to the common goals.

The first results of strategy implementation showed statistical data for 2011, and some statistical data for 2016 were not available at the time of the paper writing process, so the authors of the paper evaluated the period from 2011 to 2015 - a five year period for evaluating the smart specialization progress in achieving the Europe 2020 targets.

The authors of the paper illustrate the progress of achieving the Europe 2020 targets in Estonia, Latvia, Lithuania and the EU by using charts, which show cumulative absolute increases/decreases for each of the headline indicators and the targets to be achieved in 2020 (Ministry of Welfare, 2016).

The charts show the values for each target indicator and how fast the progress was made from 2011 to 2020 as well as each country's national target value. Such charts let us compare the progress made towards each target between the Baltic States and the EU as a whole. All the values are calculated using the data from the Eurostat database.

Some countries have defined their targets with different measurement units or base years - in the case of greenhouse gas emissions, the base year 1990 was used for the EU average level, while the Baltic States have set their targets as a percentage compared with year 2005 levels. Speaking about poverty rates, Estonia has set its target as a percentage, while Latvia and Lithuania as a number of people. To illustrate these data graphically, all the values were recalculated in percentage. Lithuania and the EU have set the shares of early school leavers at less than 9 and 10 percent, respectively. The EU has set the share of the younger generation with a tertiary degree at more than $40 \%$, while Latvia at $34-36 \%$. To illustrate the difference between the indicator values and the target values, the authors used exact values and the average value of $35 \%$ for the tertiary education rate in Latvia.

\section{RESEARCH RESULTS AND DISCUSSION}

The progress of achieving the Europe 2020 targets is illustrated in 8 charts showing cumulative absolute changes from 2011 to 2015 and the target values for the year 2020 for each country and the EU as a whole. These charts also allow evaluating the progress among the Baltic States and comparing it with the average EU. 


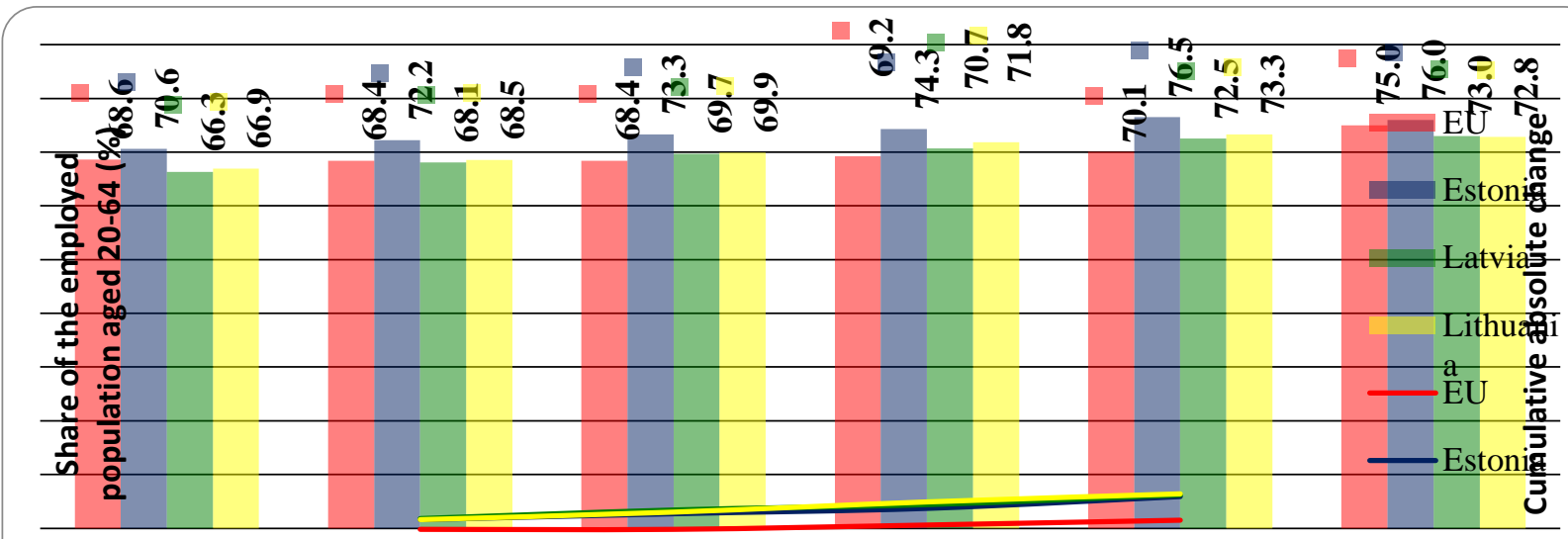

Source: authors' construction based on Eurostat data

Figure 1. The share of employed population aged 20-64 (\%) and cumulative absolute change (line).

For the Baltic States, the employment rates are very good and as seen in Figure 1, already in 2015 Estonia and Lithuania has reached their Europe 2020 target value, while Latvia was close to it. All activities especially related to EU funding are aimed at achieving the Europe 2020 targets. As regards the EU as a whole, the employment rate was growing slowly because of slow recovery from the economic crisis in 2008 (Europe 2020, 2010). In the EU the situation can be improved by more active labour market policies coupled with lifelong learning strategies and comprehensive integration policies (Taking stock..., 2014).

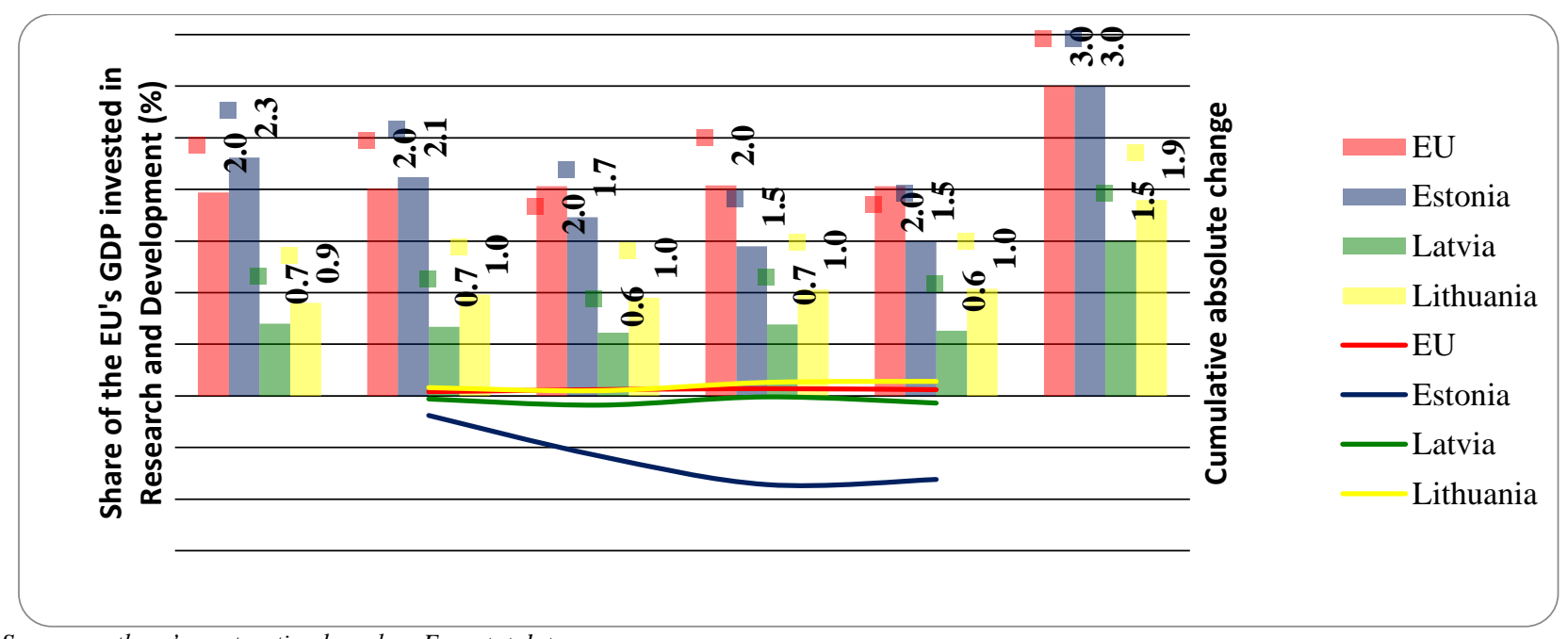

Source: authors' construction based on Eurostat data

Figure 2. The share of the EU's GDP invested in R\&D (\%) and cumulative absolute change (line).

A less positive situation is observed with regard to the share of GDP invested in R\&D. One of the reasons is the lower levels of private investment. Investment in R\&D in Estonia in 2011 and 2012 was more than twice as much as in Latvia and Lithuania, and Estonia was one of the EU Member States which stood above the EU average in this area until 2012 (Taking stock..., 2014). This high indicator value has an explanation - it was mainly due to one one-off investment made by Energy Estonia in a shale-oil testing facility that was recorded as a private R\&D investment due to statistical procedures. Therefore, over the next years R\&D intensity in Estonia decreased to some extent, with a small increase in 2015 (Assessment of..., 2013). Lithuania in this period had a small increase each year, while Latvia's indicator was varying but in general decreasing. All the three Baltic States are admitting that it is unlikely to reach the target level due to the low level of private investment in Lithuania and Latvia and due to the lack of skilled personnel and low sciencebusiness cooperation in Estonia. To improve the current indicators in the whole EU, it is necessary to focus on the effect and composition of research spending and on improving the conditions for private sector R\&D (Europe 2020, 2010).

As seen in Figure 3, the EU target of decreasing greenhouse gas emissions was already achieved in 2014, although the Baltic States had higher rates of achieving this target. Estonia reached its target in 2013, and later the rate was increasing. By the way, all the three Baltic States expect to observe the limit and reach the target. Current climate and energy policies in the EU have delivered on progress, with the economic slowdown also having a significant effect on emissions' reduction (Taking stock..., 2014). 

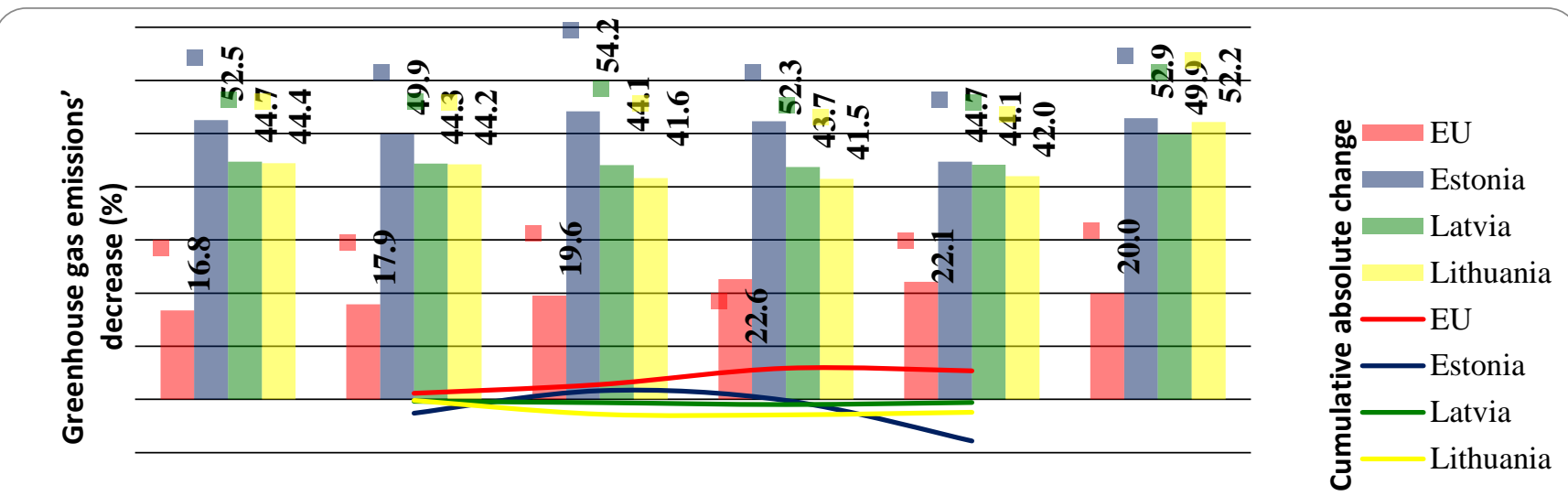

Source: authors' construction based on Eurostat data

Figure 3. The greenhouse gas emission decrease rate (\%) and cumulative absolute change (line).

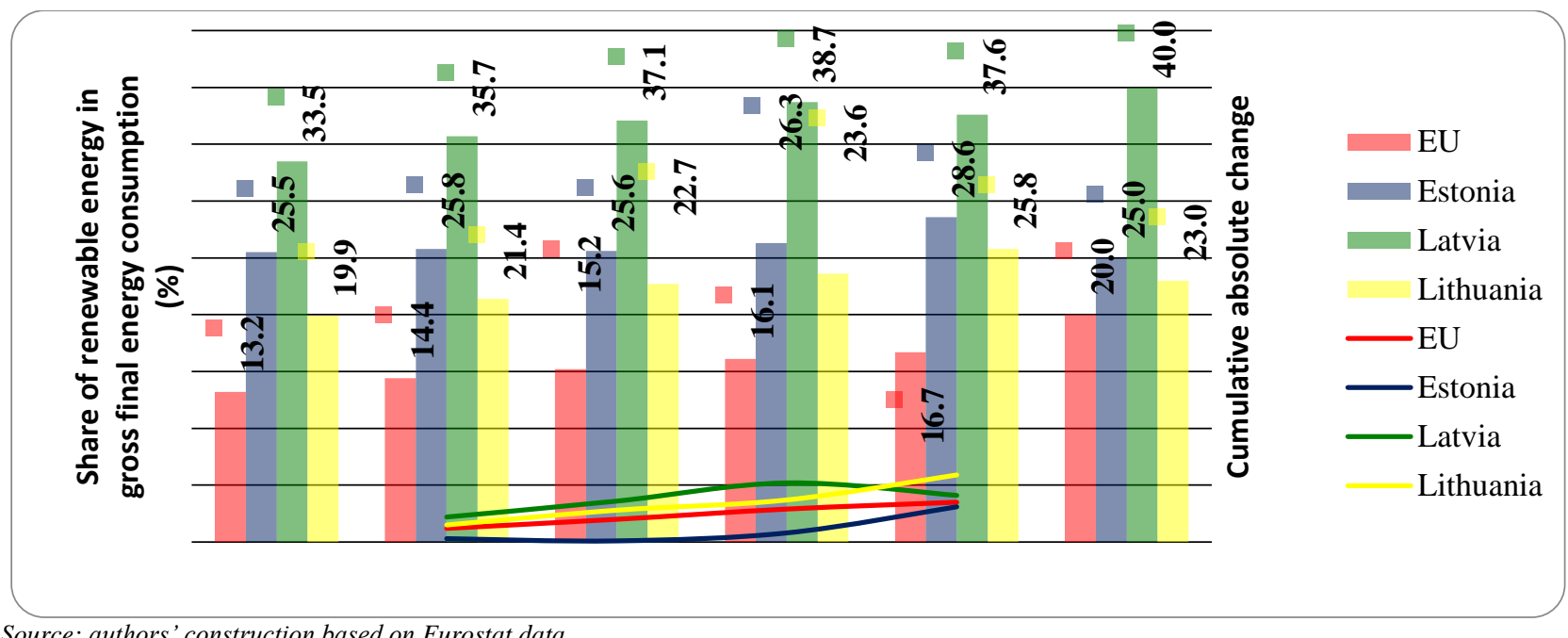

Source: authors' construction based on Eurostat data

Figure 4. The share of renewable energy in gross final energy consumption (\%) and cumulative absolute change (line).

The share of renewable energy in gross energy consumption shows very good progress. Estonia and Lithuania have already reached their targets and Latvia is on the way to soon reach its target, which is twice as high as the EU target and a little less than twice as high as the targets of Lithuania and Estonia. So Latvia is showing the best performance in this area. The notable progress of renewable energy means that the EU is the world's leader in terms of global investment in renewable energy (Taking stock..., 2014).
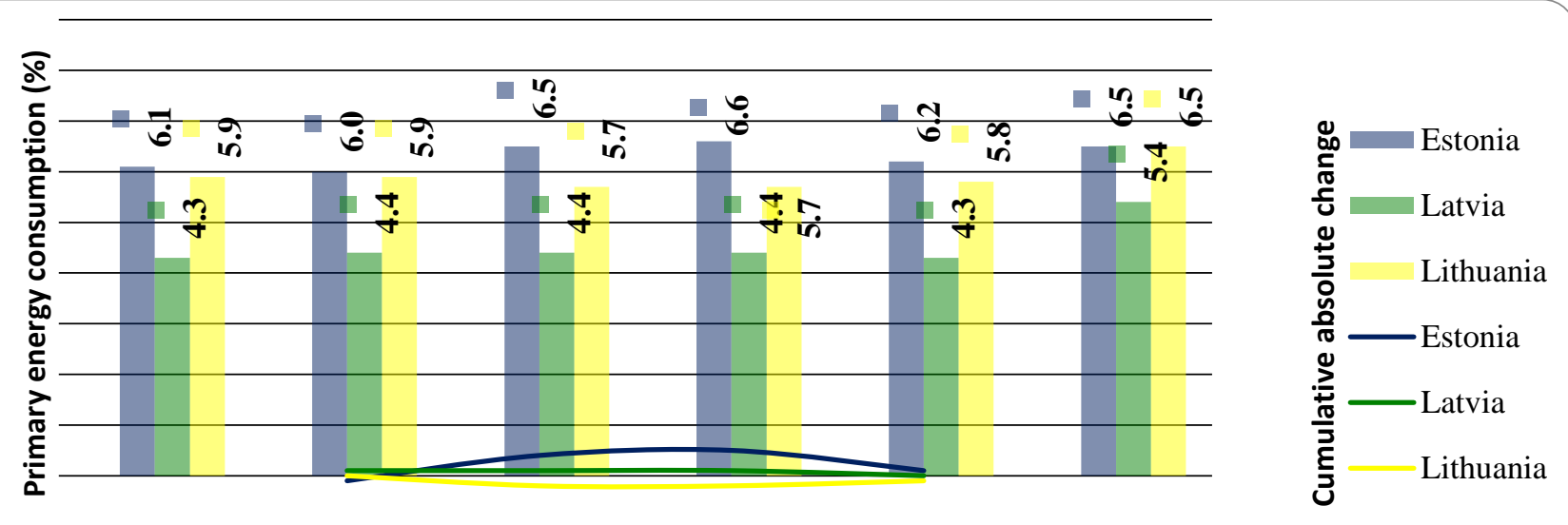

Source: authors' construction based on Eurostat data

Figure 5. Primary energy consumption (\%) and cumulative absolute change (line). 
The EU notes that the EU energy efficiency target is not on track, so there are different energy efficiency conditions from 2014. The Energy Efficiency Directive defines that the "target shall be at least equivalent to achieving new savings each year of $1.5 \%$ of the annual energy sales" (European Parliament, 2012).

As seen in Figure 5, in 2014 Estonia had reached its national target, while in Latvia and Lithuania no significant progress occurred in this area. The problem of the Latvian and Lithuanian energy markets is their high dependence on foreign energy products - gas and oil imports (EUR-Lex, 2015a; EUR-Lex, 2015b). In the whole EU the intensity for improving the performance should be higher as well.

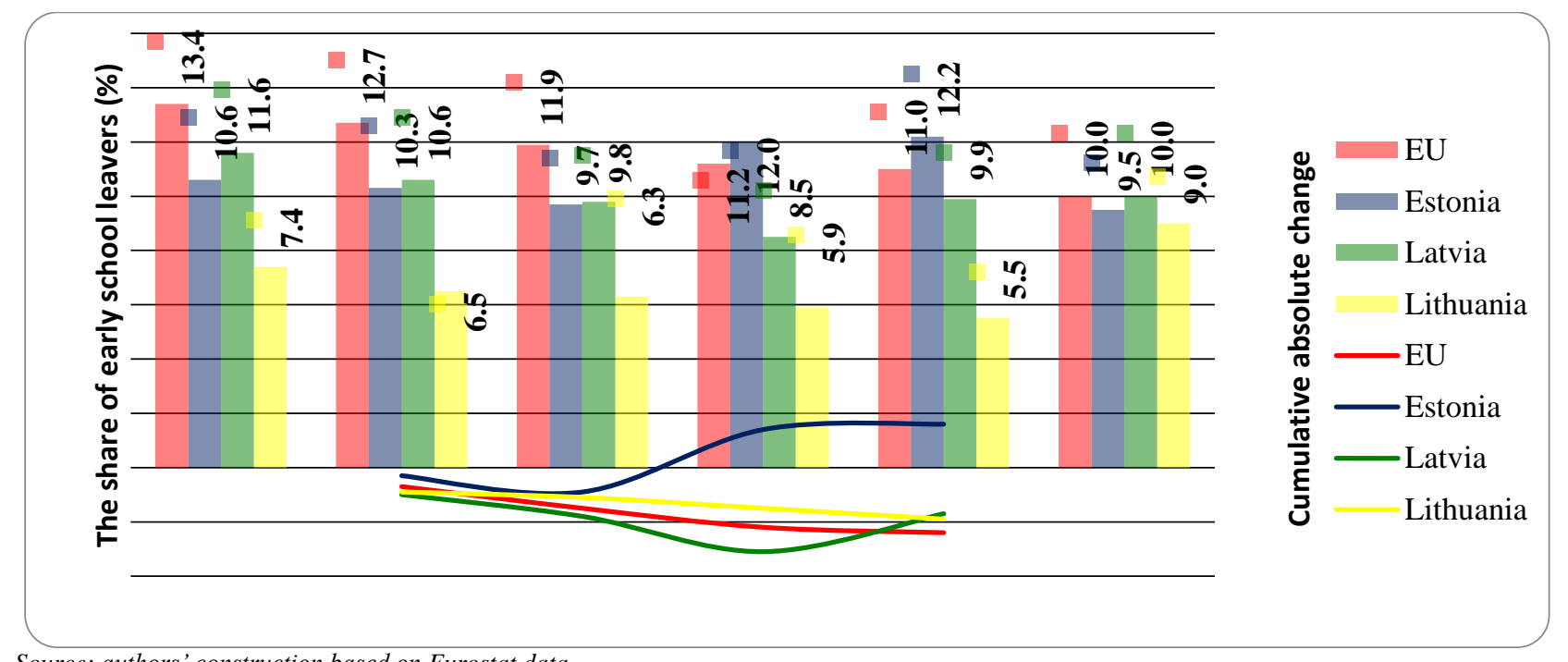

Source: authors' construction based on Eurostat data

Figure 6 . The share of early school leavers (\%) and cumulative absolute change (line).

Already at the beginning of this period Lithuania's performance was above its target and each year was improving the performance. Latvia has reached its target, and Estonia is slowly moving towards the target. The rate differs by gender the rate for males has fallen significantly, but still remaining more than twice as high as the rate for females - and also if it is rural or urban area. The high rates could be explained by strong and increasing investments in education and a favorable parental environment.
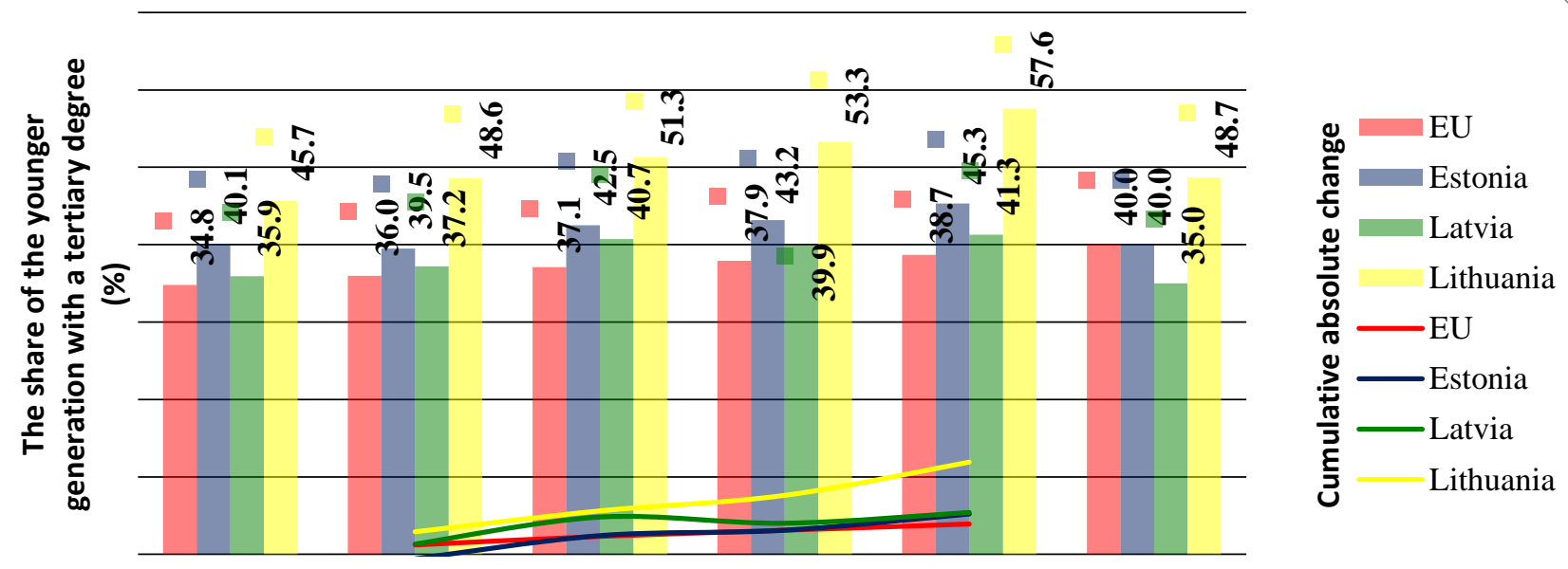

Source: authors' construction based on Eurostat data

Figure 7. The share of the younger generation with a tertiary degree (\%) and cumulative absolute change (line).

All the three Baltic States have very good rates for both education targets - even in the first years of the period, the rates were higher than the target values and they kept increasing. Besides, the Baltic rates were higher than the EU average target for 2020. In 2015, the share of the younger generation with a tertiary degree in Latvia was $41.3 \%$ and in Estonia $45.3 \%$, while in Lithuania the share was one of the highest in the EU $-57.6 \%$. It means that a highly educated younger generation lives in the Baltic States. 

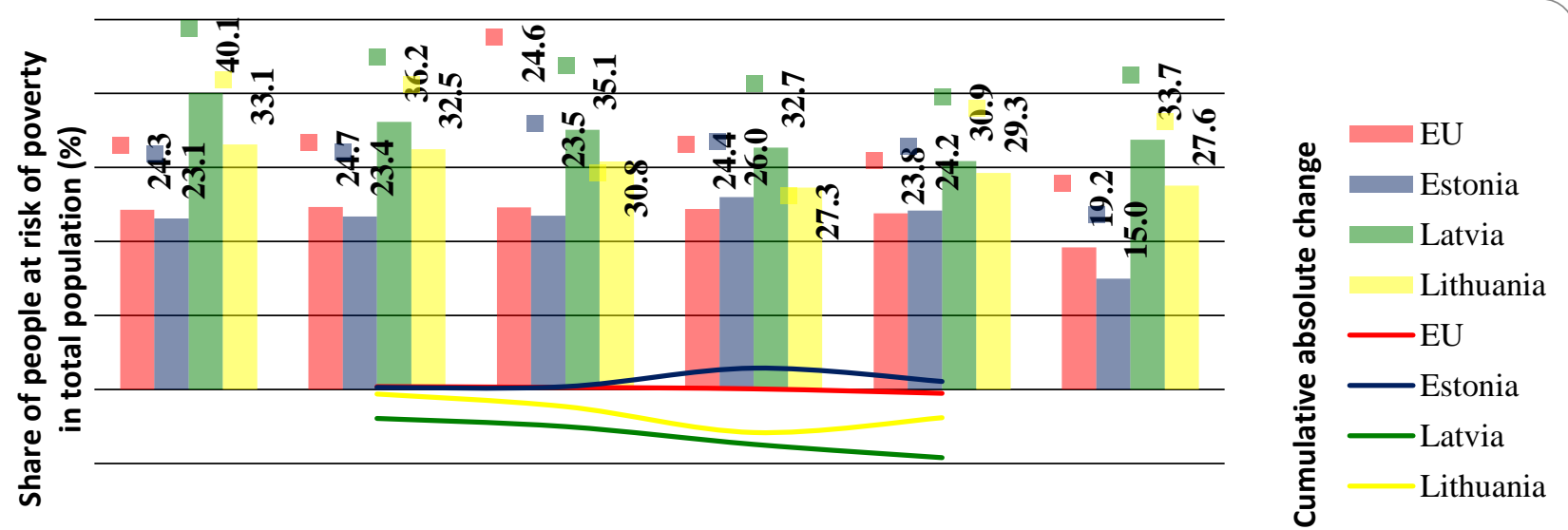

Source: authors' construction based on Eurostat data

Figure 8. The share of people at risk of poverty in total population (\%) and cumulative absolute change (line).

The rate in the whole EU was low and the situation for reaching target is challenging. Besides, Estonia has set a high target value, the employment and income targets were also increased, therefore meeting the target in 2020 is most likely impossible. Reaching the target by 2020 requires additional measures to further increase participation in the labor market, and improve skills and qualification levels due to increased employment and income. Latvia and Lithuania have already met their targets, and they keep the rates while increasing economic growth.

\section{CONCLUSIONS}

Smart specialization strategy implementation in the EU has influenced such fields of development as education, investment in R\&D and employment.

The Baltic States have already reached their national targets or are very close to reach them in such areas as employed population, renewable energy and tertiary education.

Progress in the Baltic States is also depending on the target value set - in relation to some targets, one of the Baltic States has set a twice as high target than the others: Estonia has set a two times higher target value than Latvia with regard to the share of GDP invested in R\&D, while Latvia has set almost two times higher target value than Estonia, Lithuania and the EU regarding the share of renewable energy. .

The Baltic States have showed very good progress in achieving the education targets - Lithuania has the highest progress regarding the share of the younger generation with a tertiary degree in the whole EU.

One significant one-off investment in R\&D in Estonia in 2011 could cause a considerable increase in the share of GDP invested in R\&D, demonstrating a rate twice as high as in Latvia and Lithuania.

Forecasting progress regarding the Europe 2020 targets, one can conclude the target values will be reached in all the areas, except energy consumption and poverty in Estonia and the EU that have not significantly progressed in the 5 year period.

\section{ACKNOWLEDGEMENTS}

The research was supported by the project "Strengthening Research Capacity in Latvia University of Agriculture" (agreement No 3.2.-10/43).

\section{REFERENCES}

1. EUR-Lex. 2015. State of the Energy Union (2015) Country Factsheet Lithuania. Commission Staff Working Document. Available at http://eur-lex.europa.eu/legal-content/lt/TXT/?uri=CELEX:52015SC0231 (Accessed on 01/11/2017).

2. EUR-Lex. 2015. State of the Energy Union (2015) Country Factsheet Latvia. Commission Staff Working Document. Available at http://eur-lex.europa.eu/legal-content/EN/TXT/?qid=1510734384871\&uri=CELEX:52015SC0230 (Accessed on 01/11/2017).

3. European Commission. 2013. Assessment of the 2013 national reform programme and stability programme for ESTONIA. European Commission staff working document. Available at http://eur-lex.europa.eu/legalcontent/lv/TXT/?uri=CELEX:52013SC0356 (Accessed on 01/11/2017).

4. European Commission. 2010. EUROPE 2020: A European strategy for smart, sustainable and inclusive growth. Available at http://ec.europa.eu/eu2020/pdf/COMPLET\%20EN\%20BARROSO\%20\%20\%20007\%20-\%20Europe\%202020\%20\%20EN\%20version.pdf (accessed on 10/12/2016).

5. European Commission. 2014. Taking stock of the Europe 2020 strategy for smart, sustainable and inclusive growth. Communication from the Commission to the European Parliament, the Council, the European Economic and social committee and the Committee of the Regions COM/2014/0130. Available at http://eur-lex.europa.eu/legalcontent/EN/ALL/?uri=celex:52014DC0130 (Accessed on 06/11/2017). 
6. European Council. 2010. Conclusions of European Council 17 June 2010. Available at http://ec.europa.eu/eu2020/pdf/council_conclusion_17_june_en.pdf (Accessed on 15/10/2017).

7. European Parliament. 2012. Directive on energy efficiency. Directive 2012/27/EU of the European Parliament and of the Council. Available at http://eur-lex.europa.eu/LexUriServ/LexUriServ.do?uri=OJ:L:2012:315:0001:0056:en:PDF (Accessed on 01/11/2017).

8. Eurostat. 2017. Smarter, greener, more inclusive? Indicators to support the Europe 2020 strategy. Available at http://ec.europa.eu/eurostat/documents/3217494/8113874/KS-EZ-17-001-EN-N.pdf/c810af1c-0980-4a3b-bfdd-f6aa4d8a004e (Accessed on 01/11/2017).

9. Jucevicius, R., Galbuogiene, A. 2014. Smart Specialization: Towards the Potential Application of the Concept for the Local Development. Procedia - Social and Behavioral Sciences, Vol. 156, pp. 141-145.

10. Ministry of Welfare of the Republic of Latvia. 2016. Time Series. Available at http://www.lm.gov.lv/upload/aktualitates/5/annex 75.pdf (Accessed on 01/11/2017). 